\title{
Aplicativo Lúdico-Pedagógico para Ensino de Programação e Robótica Educacional
}

\author{
Augusto Zanella Bardini' ${ }^{1}$, Patricia Nogueira Hübler' ${ }^{1}$ Henrique Werner Delazeri ${ }^{1}$, \\ Silvia de Castro Bertagnolli ${ }^{1}$, Pedro Henrique Rodrigues ${ }^{1}$, Leonardo de Araujo \\ Lopes ${ }^{1}$, Ígor Lorenzato Almeida ${ }^{1}$, Vitor Secretti Bertoncello ${ }^{1}$ \\ ${ }^{1}$ Instituto federal de Educação, Ciência e Tecnologia do Rio Grande do Sul (IFRS) - \\ Campus Canoas - Canoas - RS - Brazil \\ azbardini@gmail.com, patricia.hubler@canoas.ifrs.edu.br, \\ henrique.werner. delazeri@gmail.com, silvia.bertagnolli@canoas.ifrs.edu. \\ br, pedrohenrique.canoas@hotmail.com, leoalopes207@gmail.com, \\ igor.almeida@canoas.ifrs.edu.br, vitor.bertoncello@canoas.ifrs.edu.br
}

Resumo. Este artigo descreve o desenvolvimento de um aplicativo para ensino de programação, abrangendo a robótica educacional. Com o diagnóstico da alta demanda de profissionais com alto nível de raciocínio lógico e o crescente uso de dispositivos móveis pelos jovens, foi desenvolvido, com o uso de HTML, Javascript e do framework Cordova, um aplicativo de caráter lúdico-pedagógico que visa influenciar positivamente no ensino de programação. $O$ aplicativo tem o estilo de um jogo de preenchimento de lacunas e se integra, via bluetooth, com um robô Arduino. O robô Arduino é capaz de receber instruções do aplicativo e demonstra, na prática, os resultados da programação feita no aplicativo.

\begin{abstract}
This article describes the development of an application for teaching programming, encompassing educational robotics. Based on the diagnosis of high demand for professionals with a high level of logical reasoning and the rising use of mobile devices by young people, an application has been developed with the use of HTML, Javascript and the Cordova framework. The software has a ludic and pedagogical feature which aims to influence positively the teaching of programming. The application has a fill-in-theblanks game style and connects to an Arduino robot via Bluetooth. Therefore the Arduino robot is able to receive commands from the application and demonstrate the results of the programming done in the application.
\end{abstract}

\section{Cenário de uso}

Muitas são as oportunidades para profissionais qualificados da área de Tecnologia da Informação (TI) e existe o desafio, no Brasil, de atender à demanda de mão de obra do mercado de TI, que tende a ampliar sua participação no PIB em 6,5\% até 2020 [Alvarenga, 2012]. Isso implica na necessidade de abertura de cursos para formação de profissionais com conhecimentos básicos aplicados, que atendam à demanda imediata do mundo do trabalho, para possibilitar, nesse, sua rápida inserção. Entretanto, sabe-se que poucas são as pessoas interessadas em ingressar na área. 
VI Congresso Brasileiro de Informática na Educação (CBIE 2017)

Anais dos Workshops do VI Congresso Brasileiro de Informática na Educação (WCBIE 2017)

Nesse contexto, diagnosticada a demanda de profissionais com alto nível de raciocínio lógico e o crescente uso de dispositivos móveis pelos jovens, busca-se desenvolver uma solução que os incentive a utilizar dispositivos móveis para a criação de seus primeiros programas de forma fácil e intuitiva, com a aplicação direta em robôs confeccionados para este fim, já no ensino fundamental.

O objetivo do trabalho apresentado neste artigo é desenvolver um ambiente lúdicopedagógico para ensino de programação, aplicado em robôs, cuja utilização seja disponível em dispositivos Android. Ao buscar atingir o objetivo geral proposto, pretende-se atingir demais objetivos específicos de maior abrangência:

a) Desenvolver o raciocínio lógico em jovens do ensino fundamental da Rede Municipal de Ensino de Canoas;

b) Incentivar a inserção de jovens na área profissional de TI;

c) Atrair os jovens à área de programação e simplificar o desenvolvimento do raciocínio lógico a partir da criação do ambiente lúdico-pedagógico;

d) Integrar a robótica educacional à programação de sistemas computacionais.

A solução proposta visa atender a alunos dos quintos e sextos anos do ensino fundamental, em disciplinas que envolvam conceitos de física e matemática. Para isso, a definição dos primeiros problemas a serem inseridos no protótipo foram definidos em conjunto com professores que atuam diretamente com o perfil apresentado.

\section{Desenvolvimento}

O aplicativo foi implementado utilizando HTML e Javascript e convertido para a plataforma Android utilizando-se o Cordova, um framework capaz de acondicionar aplicativos HTML/JavaScript em um recipiente nativo que pode ser executado em diversas plataformas.

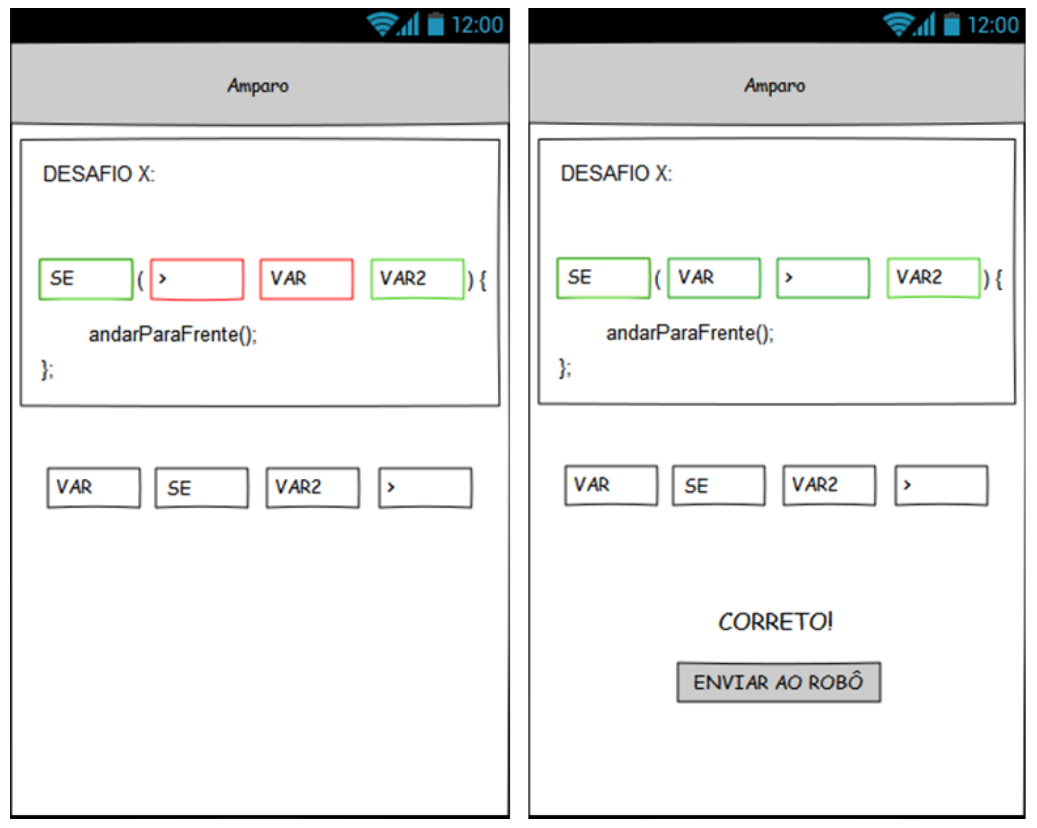

Figura 1. Protótipo de telas 
VI Congresso Brasileiro de Informática na Educação (CBIE 2017)

Anais dos Workshops do VI Congresso Brasileiro de Informática na Educação (WCBIE 2017)

Primando pela ludicidade do aplicativo, foi definido seu estilo em formato de jogo. No decorrer do jogo, o usuário se depara com funções de lógica de programação e deve preencher lacunas com as opções que lhe são apresentadas. Na Figura 1, há um protótipo de telas de como deveria ser o aplicativo.

$\mathrm{Na}$ modelagem do aplicativo, foi aplicada a UML, uma linguagem visual capaz de modelar sistemas computacionais, cujo objetivo é definir as características do software como seus requisitos, comportamento, estrutura lógica etc. [Guedes, 2014]

Para isso, fez-se uso de diagramas específicos capazes de modelar suas características. Entre eles, estão o diagrama de casos de uso, que determina as necessidades do usuário e exibe uma ideia geral de como o sistema deve se comportar. A aplicação deve seguir o seguinte diagrama de casos de uso, demonstrado na Figura 2, no qual as elipses indicam possíveis ações do usuário:

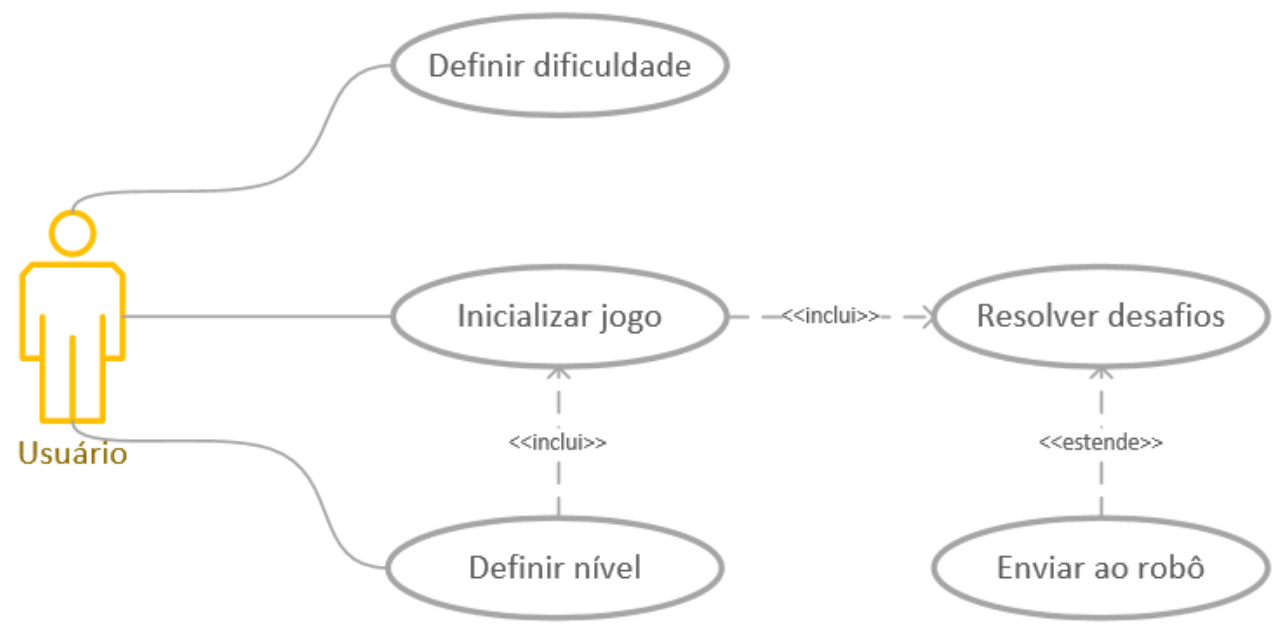

Figura 2. Diagrama de casos de uso

O usuário, ao abrir o aplicativo, pode definir a dificuldade, que determina quantas lacunas deverá preencher, e inicializar o jogo. Além disso, pode definir o nível a ser jogado e inicializar o jogo. Ao inicializar, o usuário resolve uma série de desafios apresentados, visando estimular o aprendizado de lógica de programação. Uma vez completo cada desafio, caso seja um desafio relacionado ao robô Arduino, o usuário pode enviar o comando para visualizar o resultado do desafio na prática.

\section{Apresentação do Software}

O desenvolvimento em HTML com uso de Javascript, acondicionado à realidade dos dispositivos móveis com o uso do Cordova, chegou em um resultado muito parecido com a previsão inicialmente feita. No menu principal, o usuário pode escolher entre inicializar o jogo, escolher o nível, definir a dificuldade, ou optar por uma área de programação livre, ainda em desenvolvimento (Figura 3).

Ao optar por jogar, o usuário se depara com algoritmos com lacunas não preenchidas e opções de preenchimento logo abaixo. As lacunas vão se contornando de verde ou vermelho, à medida que o usuário as preenche, para indicar se estão corretas ou erroneamente preenchidas. Essas duas telas são visualizadas na Figura 4. 
VI Congresso Brasileiro de Informática na Educação (CBIE 2017)

Anais dos Workshops do VI Congresso Brasileiro de Informática na Educação (WCBIE 2017)

Ao preencher todas corretamente, caso o algoritmo da questão seja relacionado ao robô Arduino, o aplicativo permite que as instruções sejam enviadas via Bluetooth. Na Figura 5 é possível visualizar a tela para envio dos comandos.

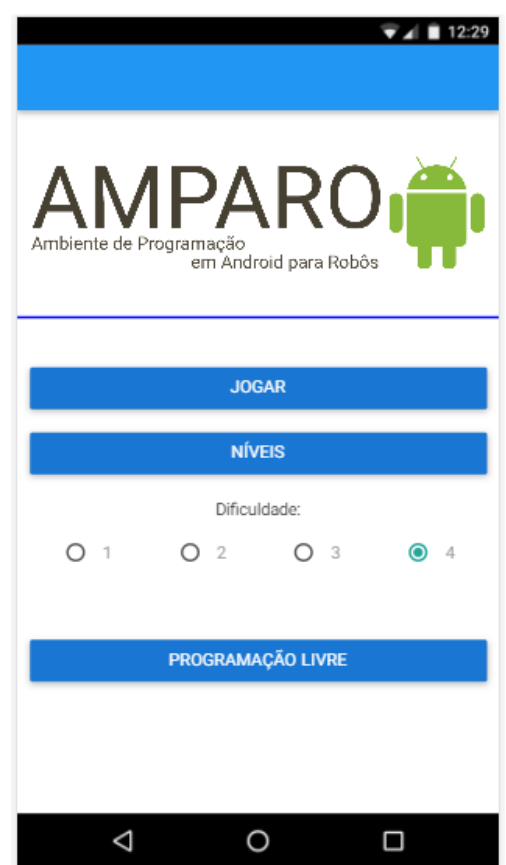

Figura 3. Tela do Menu Principal

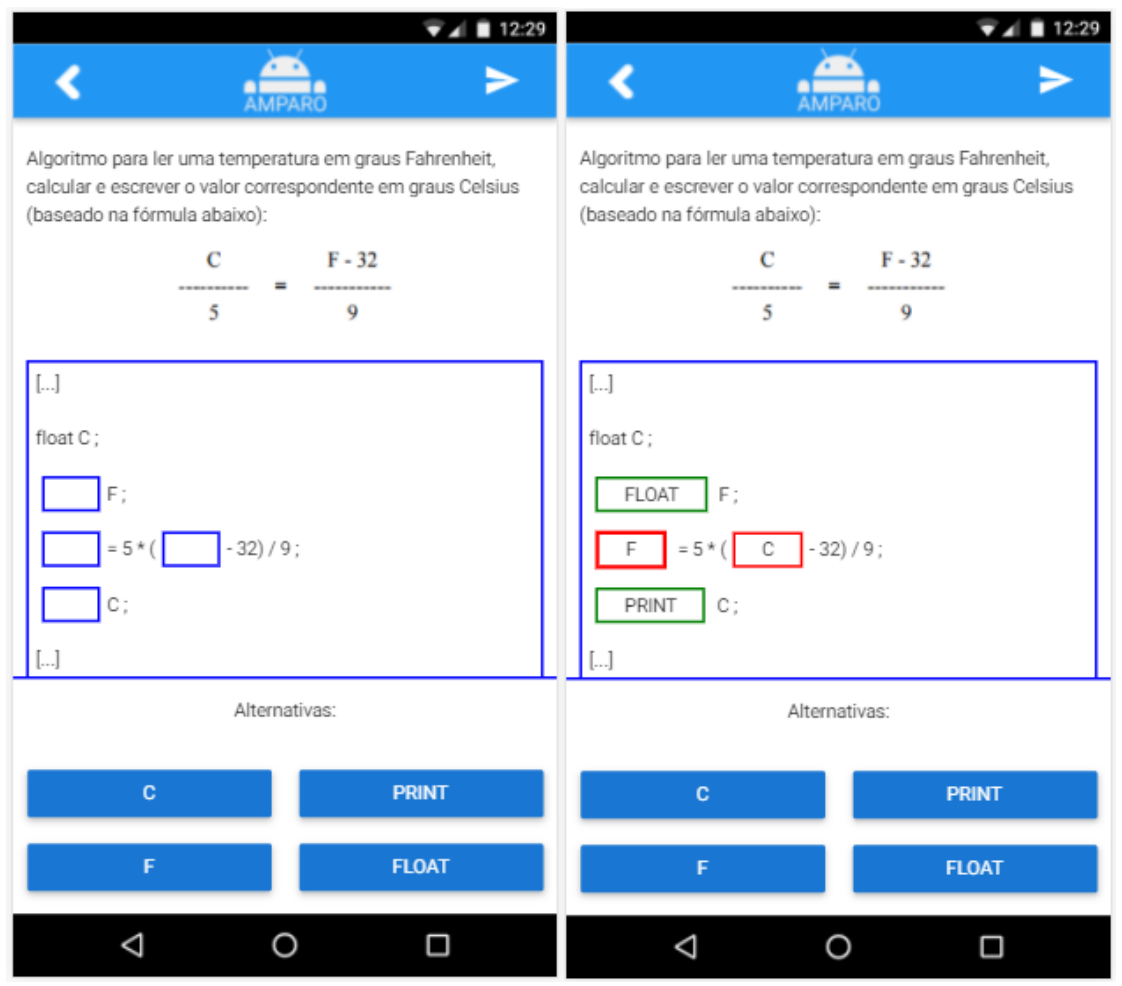

Figura 4. Possibilidade de Jogo 
VI Congresso Brasileiro de Informática na Educação (CBIE 2017)

Anais dos Workshops do VI Congresso Brasileiro de Informática na Educação (WCBIE 2017)

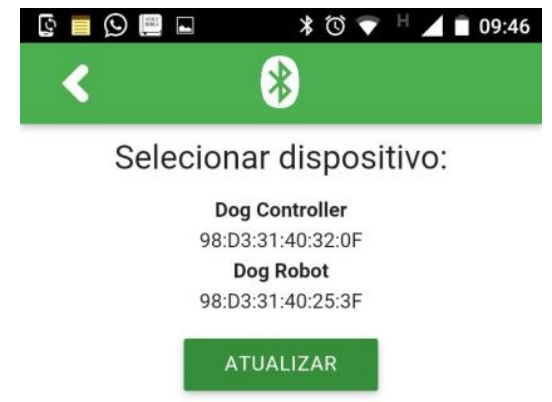

\section{$\triangleleft$ \\ ○ $\quad$}

Figura 5. Telas para Envio dos Comandos para o Robô

As instruções enviadas via Bluetooth são processadas pelo robô, que executa o código do desafio baseado no contexto do problema apresentado. Como exemplo, se o desafio envolver cálculos de física de Movimento Retilíneo Uniforme (MRU), o robô poderá demonstrar o código da resolução do desafio na prática ou, ainda, se o desafio envolver cálculos de conversão de temperatura, como o apresentado na Figura 4, o robô poderá realizar a leitura da temperatura do ambiente e apresentá-la convertida ao usuário, dando, assim, uma maior interatividade ao aplicativo. Além disso, acredita-se que a utilização de um objeto concreto, como um robô, desperte a curiosidade pela área de programação, bem como facilite o entendimento de conceitos abstratos tratados pelos desafios, uma vez que reflete a teoria na prática. Um exemplo de robô é visualizado na Figura 6.

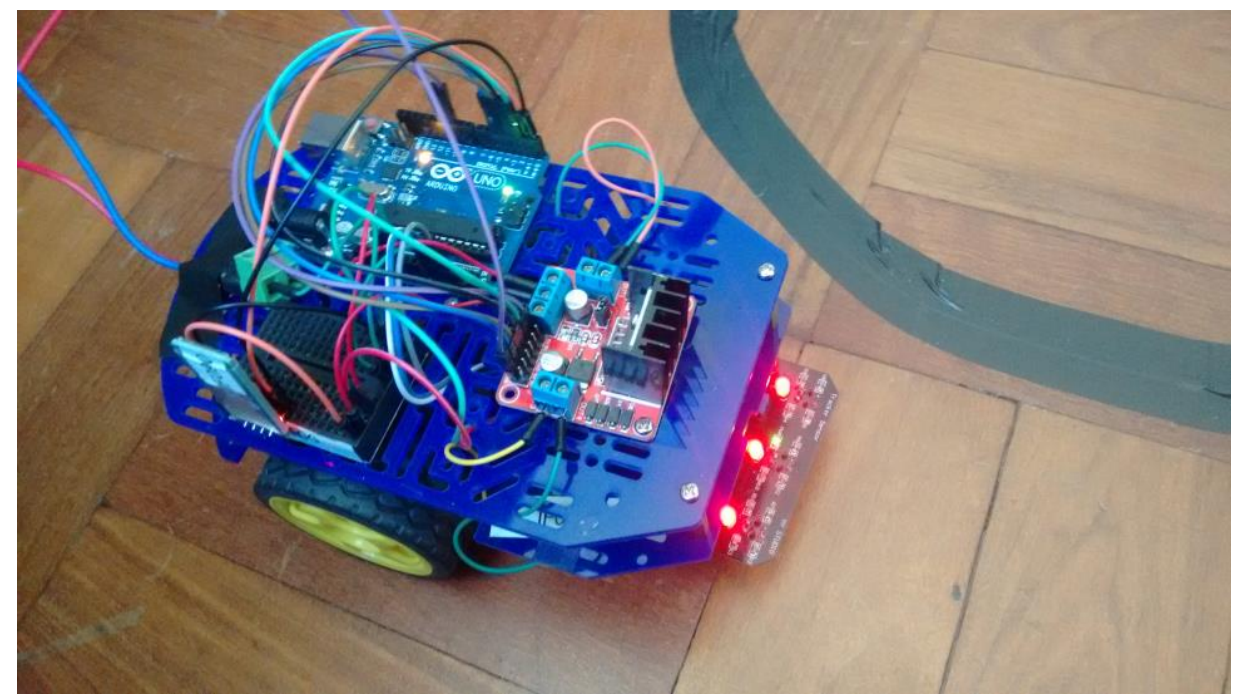

Figura 6. Robô para demonstração de conceitos de cinemática. 
VI Congresso Brasileiro de Informática na Educação (CBIE 2017)

Anais dos Workshops do VI Congresso Brasileiro de Informática na Educação (WCBIE 2017)

\section{Considerações finais}

O projeto está em fase de finalização de seu desenvolvimento, o que envolve a definição de dificuldade, a inserção de níveis, a completa integração do aplicativo com o robô e a avaliação do aplicativo. Como resultados acadêmicos do projeto, tem-se a publicação do trabalho "Desenvolvimento de aplicativo Android com integração Bluetooth", apresentado no $4^{\circ}$ SICT do IFRS e no V Salão de Iniciação Científica e Tecnológica do IFRS Campus Canoas, além do trabalho "Ambiente lúdico-pedagógico para ensino de programação em dispositivos móveis”, apresentado no VI Salão de Iniciação Científica e Tecnológica do IFRS Campus Canoas. Como trabalhos futuros, tem-se o aprimoramento das funções, a melhoria do design visual do aplicativo, e a finalização de uma área de simulação de programação livre em blocos, com direta aplicação no robô Arduino. Espera-se que o aplicativo ajude a contribuir positivamente no ensino de programação e na inserção de jovens na área da TI, uma vez que visa a utilização por alunos da rede municipal de ensino dos quintos e sextos anos.

\section{Agradecimentos}

Agradecemos ao CNPq pelo apoio financeiro e pela concessão de bolsas para o desenvolvimento deste projeto, bem como ao IFRS Campus Canoas pela disponibilização de espaço físico e pela concessão de bolsas.

\section{References}

Guedes, D. T. (2014) A UML 2 - Guia Prático. 2.ed. Novatec.

Alvarenga, D. (2012), "Sem retração, serviços de tecnologia avançam no país e alavancam

PIB", http://www.brasscom.org.br/brasscom/Portugues/detNoticia.php?codArea=2\&codCat egoria $=26 \& \operatorname{codNoticia}=53$, March. 